\title{
Effect Of The Big Five Personality Traits On Job Satisfaction And Organizational Commitment In The Healthcare Industry: The Case Of Kenya \\ Daniel Ganu, Adventist University of Africa, Kenya \\ Caleb Nyaranga Kogutu, University of Eastern Africa Baraton, Kenya
}

\begin{abstract}
The study examined the effect of the big five personality traits on job satisfaction and organizational commitment among healthcare workers in Kenya. The study utilized a correlational descriptive study design and collected data using a self-administered questionnaire. In all, 252 healthcare workers comprising Medical doctors, Nurses, Pharmacists, and Lab Technologist participated in the study. Using descriptive statistics and multi-linear regression analysis, the study showed significant relations between the Big Five personality traits with job satisfaction and organizational commitment. Openness, Conscientiousness, and Neuroticism have a positive relation with organizational commitment while extraversion and Neuroticism also have a positive relation with job satisfaction. More so, a positive relationship was found between job satisfaction and organizational commitment. This finding suggests that employees who exhibit the traits of openness, neuroticism, extraversion and conscientiousness turn to find a greater sense of commitment and job satisfaction to the Healthcare organizations. The implication of the results will be useful to hospital administrators and the healthcare industry in general.
\end{abstract}

Keywords: Job Satisfaction; Organizational Commitment; Personality Trait; Healthcare Industry

\section{INTRODUCTION}

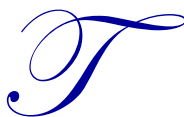

he committed employee is loyal to the organization's values and proud of being a member of its work team. In this sense, organizational commitment is a positive psychological state of attachment that pushes the employee's performance upward to successfully turn the firm's strategic vision into a reality (Porter et al, 1974, quoted by Hawass, 2012). The foundation of this study is the belief that employee job satisfaction and organizational commitment in the healthcare industry are linked with personality traits. The healthcare industry is a place where little mistakes can lead to an unacceptable loss of life and property. Due to its sense of strong mission, the healthcare industry must build its workforce that is strongly dedicated with high level of job satisfaction and commitment in order to provide quality care to patients (Baker et al, 2005). It is crucial to understand employee personality traits and how they affect organization outcomes in the healthcare industry. External influences in the work environment of the healthcare industry are moderated by the personal predispositions of the individual (Turska-Kawa, 2013), which significantly neutralizes the direct impact of the influencing agent and raises the importance of the personality factor. The study of personality determinants finds important applications in various areas of commitment in the healthcare organization. According to Peryin \& John (1999), each level of these personality traits has a unique contribution to the understanding of individual differences in behavior and experience. The individual's personality can define how he or she views the world around him, reacts to situations, and interacts with others in the organization (Michaud, 2013).

Decades of researches have correlated mood at work to generalized emotional states encountered on the job (George \& Brief, 1992). More so, moods have been shown to predict one's impression of a situation and one's own 
actions (Clark \& Isen, 1982). Evidence has been accumulated over the years that all personality measures can be categorized under the umbrella of a 5 -factor model of personality (Goldberg, 1990). The study specifically linked traits from the 5-factor model of personality to multiple dimensions of commitment in the healthcare organization. The study also examined the relationship between general commitment in the healthcare organization and the five personality traits.

\section{Organizational Commitment And Personality Traits}

Personality embodies a person's feelings, thoughts, and behavioral patterns. Every employee has a unique personality that differentiates him or her from the other. To manage effectively, it is helpful to understand the personalities of different employees. On the other hand, an employee's commitment to the organization and job satisfaction play a central role of their retention in the field of healthcare practice, as a dissatisfied employee will be more likely to leave the healthcare field. The stress and demand that are exerted on the healthcare practitioners is such that turnover could be extremely high if employees are not satisfied with their job.

\section{Extraversion}

Extraversion is the dimension of personality associated with dominance, self-confidence and search for excitement. Extravert traits include being outgoing, talkativeness, social poise, assertiveness, and enjoying being in social situations (Carpenter, Bauer, \& Erdogan, 2010). Extraverts show a high level of positive emotions and interpersonal connections (Bakker et al, 2006). While individuals low in extraversion appear quiet or reserved, those high in extraversion are cheerful and energetic (Pervin \& John, 1990), possibly because they engage in more activities to overcome stressful conditions. Further, extraverts can easily find new job alternatives because of their diverse social connections (Erdheim et al., 2006).

\section{Openness}

Openness experience refers to the intelligence, curiosity and imagination of the individual. It represents the degree to which a person is curious, original, intellectual, and creative and how an individual can produce original ideas (Bakker et al, 2006). People high in openness seem to thrive in situations that require flexibility and learning new things. They are highly motivated to learn new skills and they do well in training settings (Lievens, Harris, Van, Bisqueret, 2003). They regard successful work accomplishment as a matter of personal identity and pride (Rostan, 1998). Creative people prefer a work environment characterized by autonomy, minimal distractions and reduced time constraints (Mumford, 2002).

\section{Neuroticism}

Neuroticism describes the person who is dramatically affected by negative life events (Bozionelos, 2003). They reflect feelings of distress and nervousness and it is the most pervasive trait across personality measures (Judge, Higgins, Thoresen, Barrick, 1999). They are depressed, tense and worry a lot about different life circumstances. Similarly, they are in short of positive psychological adjustment and emotional stability (Judge et al., 2002). In general, individuals higher in neuroticism possess more negative views of themselves and of others.

\section{Agreeableness}

Agreeableness represents the helpful, forgiving and trusting personality and they often show respectable work behavior (Organ and Lingl, 1995). Also, Judge et al (1999) found that people who score high in agreeableness 'prioritize' relationships with others over work and career success.

\section{Conscientiousness}

This dimension represents the individual who works efficiently and tends to be a reliable worker. The conscientious employee perseveres until the task is finished (John and Srivastava, 1999). That is why this individual is considered the most consistent predictor of performance across jobs. 


\section{Theoretical Framework}

From a wider perspective, the study is built on the framework of Holland's theory (Holland, 1985) - which has been widely and extensively researched - that individuals gravitate toward, are satisfied with, and persist in occupations and settings where there is a good fit between their personality and the environment in which they work (Schneider, 1987). Further, the foundation of the study is also built on the belief that the big five personality traits are linked with employee job satisfaction and organizational commitment in the healthcare industry. George and her colleagues (George, 1989, 1991; George \& Brief, 1992; George \& Jones, 1996) reported significant findings demonstrating that positive and negative moods of employees influence their feelings about work and their behaviors on the job.

\section{METHODS}

The study adopted descriptive correlational study design where relationships between the big five personality traits, job satisfaction and organizational commitment were examined. We used a sample of 252 healthcare workers in Kenya drawn from public and private health facilities as well as from non-governmental organizations. Medical doctors, nurses, clinical officers, pharmacists, medical laboratory technologists and health counselors, who had worked in their respective organizations for more than six months, were eligible for participation.

Disproportional stratified random sampling was employed where participants were selected as per the four levels (Strata) of healthcare structure in Kenya. According to Kenya Health Policy (2012-2030), the healthcare in Kenya is structured as follows:

- Tier 1 - community health units and non-governmental organizations offering preventive and minor treatments services

- $\quad$ Tier 2 - primary care level, providing outpatient health services and they receive patients from Tier-1

- $\quad$ Tier 3 - county level which provides primary referral services, offering curative and rehabilitative services

- $\quad$ Tier 4 - National referral hospitals providing secondary and specialized services

A questionnaire with closed-ended questions was self-administered by the research assistants during the regular work hours to the randomly selected participants after obtaining an informed consent from them. The questionnaire comprised of four items: 1) the demographic profile of the participants, 2) five-factor personality traits, 3) dimensions of organizational commitment, and 4) job satisfaction in a five-point Likert type scale that was used to measure the objectives of the study. Employees on probation were excluded from the study; i.e., those with less than 120 days within the organization/institutions. The data analysis was performed using Statistical Package for Social Sciences (SPSS) version 20 software (SPSS Inc., Chicago, Illinois, USA).

Descriptive statistics was used to describe the characteristics of the sampled participants while multi linear regression was used to test the relationship/effect of the big five personality traits on the job satisfaction and organizational commitment of the healthcare workers in Kenya.

\section{RESULTS}

Table 1 presents a multi linear regression analysis indicating a relationship between personality traits and organizational commitment. The study utilized 252 respondents from the healthcare industry with the highest percentage $(67.6 \%)$ working as nurses. The rest are lab technologists $(12.4 \%)$, medical doctors $(7.1 \%)$, midwives (6.2\%), pharmacists $(4.0 \%)$, and counselors (2.6\%). About 57\% fall within the age bracket of $31-40$ years with $71 \%$ female and $29 \%$ male. Also, $66 \%$ indicated that they are given the opportunity to utilize their skills and talents at work and $65 \%$ said their supervisors give feedback for them to improve and achieve their goals. On the other hand, $34 \%$ said that they have experienced some degree of discrimination and tribalism at their place of work. 
Table 1: Personality Traits And Organizational Commitment

\begin{tabular}{|l|c|c|c|c|}
\hline \multirow{2}{*}{\multicolumn{1}{c|}{ Effect }} & Model Fitting Criteria & \multicolumn{2}{c|}{ Likelihood Ratio Tests } \\
\cline { 2 - 6 } & $\begin{array}{c}\text {-2 Log Likelihood } \\
\text { of Reduced Model }\end{array}$ & Chi-Square & df & \multirow{2}{*}{ Sig. } \\
\hline Intercept & 200.741 & 31.539 & 2 & .000 \\
\hline Openness & 175.255 & 6.053 & 2 & .048 \\
\hline Conscientiousness & 185.257 & 16.055 & 2 & .000 \\
\hline Extraversion & 169.579 & .378 & 2 & .828 \\
\hline Agreeableness & 170.172 & .971 & 2 & .616 \\
\hline Neuroticism & 191.099 & 21.898 & & 2 \\
\hline
\end{tabular}

The results showed that openness, conscientiousness, and neuroticism personality traits correlate positively with organizational commitment. Pearson correlations analysis (Table 2) also showed that extraversion personality trait correlates positively $(\mathrm{r}=0.127, \mathrm{p}<0.45)$ with job satisfaction. More so, neuroticism correlates with job satisfaction $(r=0.269, \mathrm{p}<0.001)$. Conversely, openness, conscientiousness, and agreeableness did not show any positive correlation. Klaus (2012) found, in his study, that all personality scales correlated significantly with job satisfaction, with the strongest correlations for agreeableness, conscientiousness, and neuroticism with openness scoring the weakest correlation.

Table 2: Job Satisfaction And Personality Variables

\begin{tabular}{|c|c|c|c|c|c|c|c|}
\hline \multicolumn{8}{|c|}{ Correlations } \\
\hline & & 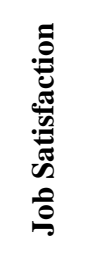 & 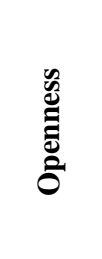 & 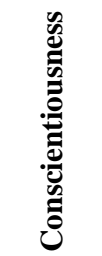 & 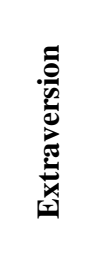 & 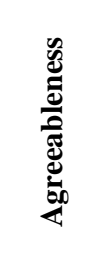 & 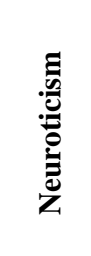 \\
\hline \multirow[t]{3}{*}{ Job Satisfaction } & $\begin{array}{l}\text { Pearson } \\
\text { Correlation }\end{array}$ & 1 & .085 & .083 & $.127^{*}$ & -.051 & $.269^{* *}$ \\
\hline & Sig. (2-tailed) & & .180 & .193 & .045 & .426 & .000 \\
\hline & $\mathrm{N}$ & 248 & 248 & 248 & 248 & 248 & 248 \\
\hline \multirow{3}{*}{ Openness } & $\begin{array}{l}\text { Pearson } \\
\text { Correlation }\end{array}$ & .085 & 1 & $.170 * *$ & $.157 *$ & $.218 * *$ & $.269 * *$ \\
\hline & Sig. (2-tailed) & .180 & & .007 & .013 & .000 & .000 \\
\hline & $\mathrm{N}$ & 248 & 252 & 252 & 252 & 252 & 252 \\
\hline \multirow{3}{*}{ Conscientiousness } & $\begin{array}{l}\text { Pearson } \\
\text { Correlation }\end{array}$ & .083 & $.170 * *$ & 1 & $.483 * *$ & $.361 * *$ & -.100 \\
\hline & Sig. (2-tailed) & .193 & .007 & & .000 & .000 & .114 \\
\hline & $\mathrm{N}$ & 248 & 252 & 252 & 252 & 252 & 252 \\
\hline \multirow{3}{*}{ Extraversion } & $\begin{array}{l}\text { Pearson } \\
\text { Correlation }\end{array}$ & $.127 *$ & $.157 *$ & $.483 * *$ & 1 & $.259 * *$ & -.049 \\
\hline & Sig. (2-tailed) & .045 & .013 & .000 & & .000 & .437 \\
\hline & $\mathrm{N}$ & 248 & 252 & 252 & 252 & 252 & 252 \\
\hline \multirow{3}{*}{ Agreeableness } & $\begin{array}{l}\text { Pearson } \\
\text { Correlation }\end{array}$ & -.051 & $.218 * *$ & $.361 * *$ & $.259 * *$ & 1 & $-.157 *$ \\
\hline & Sig. (2-tailed) & .426 & .000 & .000 & .000 & & .013 \\
\hline & $\mathrm{N}$ & 248 & 252 & 252 & 252 & 252 & 252 \\
\hline \multirow{3}{*}{ Neuroticism } & $\begin{array}{l}\text { Pearson } \\
\text { Correlation }\end{array}$ & $.269^{* *}$ & $.269 * *$ & -.100 & -.049 & $-.157 *$ & 1 \\
\hline & Sig. (2-tailed) & .000 & .000 & .114 & .437 & .013 & \\
\hline & $\mathrm{N}$ & 248 & 252 & 252 & 252 & 252 & 252 \\
\hline
\end{tabular}


Table 3 presents Pearson correlation between job satisfaction and organizational commitment.

Table 3: Job Satisfaction And Organizational Commitment

\begin{tabular}{|l|l|c|c|}
\hline \multicolumn{2}{|c|}{ Correlations } & $\begin{array}{c}\text { Professional Commitment } \\
\text { To The Organization }\end{array}$ \\
\hline \multirow{3}{*}{ Job Satisfaction } & & Job Satisfaction & $.521^{* * *}$ \\
& Pearson Correlation & 1 & .000 \\
\cline { 2 - 4 } & Sig. (2-tailed) & & 245 \\
\cline { 2 - 4 } $\begin{array}{l}\text { Professional Commitment To The } \\
\text { Organization }\end{array}$ & $\mathrm{N}$ & $.521^{* *}$ & 1 \\
\cline { 2 - 4 } & Pearson Correlation & .000 & 248 \\
\cline { 2 - 4 } & $\mathrm{N}$ & 245 & \\
\hline$* *$ Correlation is significant at the 0.01 level (2-tailed). & & \\
\hline
\end{tabular}

The results showed that those who are satisfied with their job also turn to having a high organizational commitment, which, in a way, is the emotional attachment people have toward their organization of work. There is definitely a high degree of similarities and overlapping that can be found between job satisfaction and organizational commitment (Bauer \& Erdogen, 2010) because those things that make one satisfied with his or her work are almost the same that makes one more committed to the organization. Assessing the work environment fully cannot yield job satisfaction. Connolly \& Viswesvaran (2000) have shown that job satisfaction is not purely environmental and is partially due to our personality. Some people have a disposition to be happy in life and at work regardless of environmental factors.

\section{DISCUSSION}

In the healthcare industry, it is relevant to know which personality traits strongly predict health worker satisfaction and commitment. In this study, conscientiousness, openness, and neuroticism personality traits correlate positively with organizational commitment. This means that healthcare workers who posses these traits to some degree will show commitment to the organization. Levy \& Lounsbur (2010) suggest that performers who are extraverted and conscientious are effective at managing general stress - and performance stress, in particular - and find a greater sense of satisfaction with their job. Those with the conscientiousness personality trait are naturally organized and hard-working and are a top predictor of job performance and success (Judge et al., 2002). It is the most stable trait (Judge, Higgins, Thoresen, \& Barrick, 1999) with mental ability for career success across the life span. It has been proven that the conscientiousness trait is consistently associated with higher level of job performance, greater frequency of desirable on-the-job behaviors, and fewer problematic work behaviors (Barrick et al., 2001; Salgado, 1997). In this sense, the personal qualities of the conscientious employee can strongly drive his or her personal attitudes toward the organization.

Meyer \& Allen (1996) indicated that commitment, as a psychological state, has at least three separable components reflecting:

- A desire (affective commitment): The affectively committed individual has a desire to stay in the organization. The employee feels a strong sense of belonging to the organization and he or she is emotionally (Hawass, 2012) attached to it. In other words, the organization represents a 'great deal of personal meaning' to the individual. Meyer and Herscovitch (2001) emphasize that the employee develops a psychological attachment to the organization when he or she recognizes the relevance or congruence of organizational values to one's own values. This means that the emotional tie gets stronger when the employee derives his/her personal identity from working with an organizational entity.

- $\quad$ A need (continuance commitment): This is based on the calculation of the person's conduct to realize the extent to which he or she needs to stay in the organization. If the available job choices after leaving the organization are scarce, the individual may develop a sense of commitment. Therefore, continuance commitment to an organization develops when an employee perceives the costs of leaving it to be higher than the expected gains.

- Obligation (normative commitment): Some employees regard commitment to a specific organization as an 
obligation. Normative commitment reflects the psychological state through which an employee perceives staying in the organization as a morally right choice, regardless of the amount of satisfaction the firm gives the employee (Marsh and Mannari, 1977). Meyer and Herscovitch (2001) propose that normative commitment increases when an individual internalizes the values of the organization and also when the individual feels that staying is a return of favor to the organization that has provided him/her many benefits and inducements over the years.

Openness, on the other hand, correlates positively with job satisfaction. Those with the openness personality trait are open to new experiences and ideas; they are creative, curious, and imaginative. They also have an advantage when they enter into a new organization. Their open-mindedness could lead them to seek a lot of information about the organization's values and benefits and they may discover, at an early stage, the advantages and disadvantages for them in the organization. This could enable them to make a quick and early adjustment to the organization to their advantage. Open people are highly adaptable to change; but on the other side, they could be prone to becoming easily bored or impatient with routine work.

Perhaps the most interesting finding is that neuroticism strongly correlated to organizational commitment and job satisfaction. Most studies found that neurotics correlate negatively with job satisfaction and organization commitment, but employees who score high in neuroticism are expected to have higher continuance commitment to the organization. In the literature of Furnham, Petrides, and Tsaousis (2005), it has been found that the neurotics are more powerfully motivated by and attracted to hygiene factors, such as job security (permanent job), benefits (good vacation, sick leave, etc.), pay (the amount of money that is paid), and work conditions (comfortable and clean). As a result, neurotics will stay with the organization because of their investment made in the organization. Neurotics may also develop fear of the costs linked with leaving their current position. That is to say, if negative events occur in neurotics' jobs, they may feel more anxious about facing a new work environment that could offer even harsher experiences (Erdheim et al., 2006). Hence, there should be a positive correlation between neuroticism and continuance commitment.

Job satisfaction is another variable that correlates highly with organizational commitment. It is the extent to which an individual enjoys his or her job (Stamps, 1997), and healthcare workers who are satisfied with their job also turn to be happy and will likely stay in their organizations. Studies (Al-Hussanini, 2008; Gregory, 2007; Jahangir \& Shokrpour, 2009; Wu \& Norman, 2006) have shown that a high level of job satisfaction contributes to a high level of organizational commitment amongst employees. This high level of organizational commitment and job satisfaction with the personality traits that showed positive correlation in this study could also be explained from the fact that $66 \%$ of the employees indicated that they are given the opportunity to freely utilize their skills and talents and also 65\% receive prompt feedback from their supervisors for self improvement. More so, $66 \%$ are given some degree of independent, autonomy and space at work to do their work which creates a positive environment for workers in the healthcare sector to feel a sense of being in control and have a sense of responsibility.

\section{LIMITATIONS}

The results of this study must be viewed in the light of some limitations. First, a larger sample size is needed to better ensure the generalizability of the current study findings. Second, the study was applied only to the Kenyan culture. The following questions could be asked: 1) "Are the same psychological constructs found in cultures as diverse as Kenya and other cultures?" and 2) Are traits organized in a similar fashion across cultures?" Accordingly, further studies are needed to confirm the generalizability of the current findings in the healthcare context. However, the study provides an initial but, to some extent, deep-down insights regarding the personality traits of committed healthcare workers in the Kenyan culture. Evidence has been found that the personality trait plays an important role in the development of organizational commitment in the healthcare industry. The study is a cross-sectional that leaves the inferences of causality questioned. Future longitudinal studies are recommended to realize the differential impact of personality traits on work-related issues across time in the healthcare industry. 


\section{CONCLUSION}

Job satisfaction and organizational commitment are at the core of the healthcare industry since this will ensure high quality service delivery. Evidence from researches points to specific determinants and correlations of job satisfaction and productivity. Dissatisfaction with one's job may result in higher employee turnover, absenteeism, slowness and grievances. Improved job satisfaction, on the other hand, results in increased productivity and organizational commitment. It should be noted, though, that the results of this study do not reveal a causal relationship. The result of the study gives more insight into the degree to which these personality traits correlate with job satisfaction and organizational commitment in the healthcare industry. Several practical implications are suggested by the findings of this study. Personality traits that make individuals successful in their careers in the healthcare industry are likely to help the healthcare organizations be successful in their endeavor. Secondly, this could be helpful to the managers of the healthcare industry to focus their attention on those personalities that showed positive correlation to manage them appropriately for achieving the mission and vision of their organizations.

\section{AUTHOR INFORMATION}

Daniel Ganu is an Associate Professor at the School of Postgraduate studies, Department of Public Health at the Adventist University of Africa, Kenya. He has served in several capacities in academia but currently is with the Adventist University of Africa as the Director for MPH program and Quality Assurance and Academic planning. He has published several research articles in international referred journals. His research interests are in children's health, drug abuse, spirituality and health, breastfeeding and health promotion. Email: ganud@aua.ac.ke.

Caleb Nyaranga is an Assistant lecturer at the school of Health Sciences, Department of Public Health at the University of Eastern Africa Baraton (UEAB), Kenya. He has served as an Environmental health officer in the Kenyan government, Ministry of Health, Department of Public Health and Sanitation and has worked as a research assistant with ADRA-Finland Foundation and UEAB - Bill and Melinda Gates Research Foundation. He is a member of the Association of Public Health Officers in Kenya. His research interests are in occupational health, environmental toxicity, health promotion, and water quality. Email: kogutucal@gmail.com.

\section{REFERENCES}

1. Al-Hussaini, M. A. (2008). Study of Nurses' Job Satisfaction: The Relationship to Organizational Commitment, Perceived Organizational Support, Transactional Leadership, Transformational Leadership and Level of Education. European Journal of Scientific Research, 22 (2): 286-295.

2. Baker, D. P., Gustafson, S., Beaubien, J., Salas, E., \& Barach, P. (2005). Medical Teamwork and Patient Safety. Retrieved from http://www.ahrq.gov/research/findings/final-reports/medteam/index.html.

3. Bakker, A. B., Van Der Zee, K. I., Lewig, K. A., \& Dollard, M. F. (2006). The relationship between the big five personality factors and burnout: A study among volunteer counselors. Journal of Social Psychology,135(5), 31-50.

4. Barrick, M. R., Mount, M. K., \& Judge, T. A. (2001). Personality and Performance at the beginning of the new millennium: What do we know and where do we go next? International Journal of Selection and Assessment, 9, 9-30.

5. Bauer, T. \& Erdogen, B. (2010). Organizational Behavior, vol. 1.0, Jupiterimages Corpoeration. Retrieved from http://catalog.flatworldknowledge.com/bookhub/reader/3?e=bauer-ch04_s01\#.

6. Bozionelos, N. (2003). The big five of personality and work involvement. Journal of Managerial Psychology, 19(1), 69-81.

7. Carpenter, C., Bauer, T., \& Erdogan, B. (2010). Personality, Attitudes, and Work Behaviors, Jupiterimages Corporation. Retrieved from http://courses.jonesinternational.edu/private/jiu/media/assets/978-1-45330090-9 Carpenter/978-1-4533-0090-9.carpenter.chapter.02.pdf.

8. Clark, M. S. \& Isen, A. M. (1982). Toward understanding the relationship between feeling states and social behavior. In A. H. Hastorf \& A. M. Isen (Eds.), Cognitive social psychology (pp. 73-108). New York, NY:Elsevier.

9. Connolly, J. J. \& Viswesvaran, C. (2000). The role of affectivity in job satisfaction: A meta-analysis. Personality and Individual Differences, 29, 265-281. 
10. Erdheim, J., Wang, M., \& Zickar, M. J. (2006). Linking the big five personality constructs to organizational commitment. Journal of Personality and Individual Differences, 41(5), 959-970.

11. Furnham, A., Petrides, K. V., \& Tsaousis, A. (2005). Cross-Cultural Investigation Into the Relationships Between Personality Traits and Work Values. The Journal of Psychology, 139 (1), 5-32.

12. George, J. M. (1989). Mood and absence. Journal of Applied Psychology, 74, 317-324.

13. George, J. M. (1991). State or trait: Effects of positive mood on pro-social behaviors at work. Journal of Applied Psychology, 76, 299-307.

14. George, J. M. \& Brief, A. P. (1992). Feeling good-doing good: A conceptual analysis of the mood at workorganizational spontaneity relationship. Psychological Bulletin, 112, 310-329.

15. George, J. M. \& Jones, G. R. (1996). The experience of work and turnover intentions: Interactive effects of value attainment, job satisfaction, and positive mood. Journal of Applied Psychology, 81, 318-325.

16. Goldberg, L. R. (1990). An alternative description of personality: The big Five factor structure. Journal of Personality and Social Psychology, 59, 1216-1229.

17. Gregory, D. M., Way, C. Y., LeFort, S., Barrett, B. J., \& Parfrey, P. S. (2007). Predictors of Registered Nurses' Organizational Commitment and Intent to Stay. Healthcare Manage Rev; 32: 119-127.

18. Hawass, H. H. (2012). Committed Salesforce: An Investigation into Personality Traits. International Journal of Business Management. Vol. 7, No. 5, Pg 147.

19. Holland, J. L. (1985). Making Vocational Choices: A theory of Vocational Personalities and Work Environments, Prentice Hall, Englewood Cliffs, New Jersey.

20. Jahangir, F. \& Shokrpour, N. (2009) Three Components of Organizational Commitment and Job Satisfaction of Hospital Nurses in Iran. Healthcare Management, 28: 375-380.

21. John, O. P. \& Srivastafa, S. (1999). The big-five trait taxonomy: History, measurement, and theoretical perspectives. To appear in Pervin, L. \& John, O. P. (Eds.), Handbook of personality: Theory and Research. New York: Guilford (in press).

22. Judge, T. \& Illies, R. (2002). Relationship of personality to performance motivation. Journal of Applied Psychology 87(4), 797-807.

23. Judge, T. A., Higgins, C. A., Thoresen, C. J., \& Barrick, M. R. (1999). The big five personality traits, general mental ability, and career success the life spans. Personnel Psychology. Vol. 52, 3; pg. 621.

24. Kenya Health Policy. (2012). Kenya Health Policy 2012-2030.

25. Levy, J. J. \& Lounsbur, John W. (2010). Big Five personality traits and performance anxiety in relation to marching arts satisfaction. Work, 40, 297-302.

26. Lievens, F., Harris, M. M., Van Keer, E., \& Bisqueret, C. (2003). Predicting cross-cultural training performance:The validity of personality, cognitive ability, and dimensions measured by an assessment center and a behavior description interview. Journal of Applied Psychology, 88, 476-489.

27. Marsh, R. M. \& Mannari, H. (1977). Organizational commitment and turnover: A prediction study. Administrative Science Quarterly, 22(1), 57-75.

28. Meyer, J. P. \& Allen, N. J. (1996). Affective, Continuance, and Normative Commitment to the Organization.

29. Meyer, J. P. \& Herscovitch, L. (2001). Commitment in the workplace: toward a general model. Human Resource Management Review, 11(3), 299-326.

30. Michaud, M. (2013). Personality a Key Factor in Healthcare Use. Retrieved from http://www.urmc.rochester.edu/news/story/index.cfm?id=3939.

31. Mumford, M. D., Scott, G. M., Gaddis, B., \& Strange, J. M. (2002). Leading creative people: Orchestrating expertise and relationships. The Leadership Quarterly, 13(6), 705-750.

32. Organ, D. W.\& Lingl, A. (1995). Personality, satisfaction, and organizational citizenship behavior. Journal of Social Psychology. Vol. 135. PP. 339-350.

33. Pervin, L. \& John, O. P. (1990). Handbook of personality: Theory and research (2nd ed.). New York: Guilford (in press).

34. Porter, L. W., Steers, R. M., Mowday, R. T., \& Boulian, P. V. (1974). Organizational commitment, job satisfaction, and turnover among psychiatric technicians. Journal of Applied Psychology, 59(5), 603-609.

35. Rostan, S. M. (1998). A study of young artists: the emergence of artistic and creative identity. Journal of Creative Behavior, 32(4), 278-301.

36. Salgado, J. F. (1997). The five factor model of personality and job performance in the European Community. Journal of Applied Psychology, 82, 30-43. 
37. Schneider, B. (1987). The people make the place, Personnel Psychology, 40, 437-445.

38. Stamps, P. L. Nurses and work satisfaction: An index for measurement. 2nd ed. Chicago, IL: Health Administration Press (1997).

39. Templer, Klaus J. (2012). Five-Factor Model of Personality and Job Satisfaction: The Importance of Agreeableness in a Tight and Collectivistic Asian Society. Applied Psychology: An International Review, $61(1), 114-129$.

40. Turska-Kawa, Agnieszka. (2013). Big Five Personality Traits Model in Electoral Behavior Studies. Romanian Journal of Political Science. Vol. 13, Issue 2, p69-105.

41. Wu, L. \& Norman, I. J. (2006). An Investigation of Job Satisfaction, Organizational Commitment and Role Conflict and Ambiguity in a Sample of Chinese Undergraduate Nursing Students. Nurse Education Today; 26: 304-314.

42. Zellars, K. L., Hochwater, W. A., Hoffman, N. P., Perrewé, P. L., and Ford, E. W. (2004). Experiencing Job Burnout: The Roles of Positive and Negative Traits and States. Journal of Applied Social Psychology. Volume 34 (5), pp. 887-911. 
NOTES 